\title{
EDITORIAL AND COMMENTARIES
}

\section{High Living}

\author{
David Sharp
}

Victory over tuberculosis in industrialized nations, sadly short-lived, owed at least as much to the regulation of residential buildings as it did to streptomycin, and the United Kingdom's National Health Service at first came under a ministerial oversight for housing. For a couple of generations, however, those two important threads in the social fabric, homes and health, have gone their separate ways. If I seek permission to extend my home, the local authority, still sensitive to the risks of respiratory and gastrointestinal infectious disease, will want to know how many persons per square meter I propose to house, and it will ask how rainwater and sewage will be disposed of, but my family's cardiovascular or mental health will not enter the equation. Recent attempts to rejoin the threads are, therefore, welcome. As Mary Northridge and her colleagues put it in this issue of Journal of Urban Health, "we need to reinvigorate the historic collaborative link between urban planning and public health professionals." This Journal's contribution is a set of reviews on what we know and what we do not know, for certain or at all, about the links between the built environment (encompassing far more than housing) and the health of those who live, work, and play in those environments.

Because the connection is so often indirect-for example, the lack of opportunity for exercise in cities or the limitations on healthy dietary choices (see Ana Diez Roux in this issue) - it would be impossible for local planning authorities to use the evidence at the level of the individual home unit, let alone a simple extension to a house, and it has to be brought to bear on bigger projects. The most obvious tool is the health impact assessment, but Northridge and colleagues note serious reservations about "institutionalizing" this process in the United States. No one wants excess bureaucracy, but some formality in what is after all the quasi-legal process of planning is unavoidable. Health (and environmental) impact assessments without teeth are meaningless. It was interesting to read of this caution at around the same time as the international banking community finally started to come to grips with social impact assessments for massive construction projects ${ }^{1}$ including hydroelectric and irrigation schemes, though too late for the Three Gorges Dam.

Another concern has to be the quality of the health impact evidence that can be set before planners. Northridge et al. describe the evidence that improving housing really does improve health as "woefully limited," and other reviews in this issue are rightly critical of the quality of different sorts of evidence. As an area for research, health and housing is notoriously difficult; random allocation to one type of housing or another is hardly ever possible and there is a constant need to correct for socioeconomic variables before ascribing differences to housing per se. Honest appraisal of the defects in evidence can only be admired, but planners may seize on it as an excuse for inertia, much as the US government has grasped at controversy 
in the climate change debate as a pretext for doing nothing about fossil fuel consumption and greenhouse gas emissions.

The UK may have done a bit better on climate change, but its track record on the health impact of big housing projects leaves much to be desired. We are learning after the event about the social and personal risks of high-rise (tower block) estates designed and administered by local authorities with the best of intentions in the 1960 s and 1970s, for the postwar housing shortage was dire, but with insufficient appreciation of the residents' wider needs. ${ }^{2}$ In Liverpool, research revealed that older people felt safe enough within these "fortresses" but not in the streets surrounding them, and fear and poor health did seem to be linked. ${ }^{3}$ Indeed, Gary Evans' review in this issue indicates that there is good evidence for an impact of the built environment, especially high-rise accommodation, on psychological health.

Some of Britain's tower blocks have been demolished, but many remain, and the pressure for new housing, especially in the southeast, is now so great that one can still, surprisingly, hear the argument that the only way is "up," unless national "greenbelt" and county structure plans (zoning in the US) are to be rewritten. In the private sector, people have a choice, and even I might quite like an apartment with a view over New York City's Central Park. It is in the area of much-needed publicsector housing, where residents have little choice, that the cardiovascular, psychological, and other evidence reviewed in this issue of the Journal should have their greatest influence, especially if high-rise is to be a popular planning option.

\section{REFERENCES}

1. International Finance Corporation. The "Equator Principles.” Washington, DC: International Finance Corporation; 2003.

2. Stewart J, Rhoden M. A review of social housing regeneration in the London Borough of Brent. J Roy Soc Health. 2003;123:23-32.

3. Green G, Gilbertson JM, Grimsley MF. Fear of crime and health in residential tower blocks: a case study in Liverpool, UK. Eur J Publ Health. 2003;12:10-15. 